\title{
TIPSTER Text Phase II Configuration Management Plan
}

\author{
Version 1.2p 3June 1996 \\ Architecture Committee \\ tipster@tipster.org
}

\subsection{EXECUTIVE SUMMARY}

This document presents the TIPSTER Text Phase II Configuration Management (CM) Plan for identifying, controlling, and auditing the TIPSTER Architecture status and configuration definition.

\subsection{Configuration Management Goals}

The CM process will support the following TIPSTER goals: use of API's, modular substitution, and conformance to applicable standards.

The CM process will document the conformance of each TIPSTER application to the Architecture Design Document and with any applicable APIs. The most important affect of the CM process will be to promote modular substitution, software re-use, and reduced risk of project planning. This will allow for the orderly upgrading of installed systems as technology improves in the future. It will also facilitate the sharing of developed software between Government agencies and offices.

\subsection{TIPSTER Application Conformance Assessment Document}

The CM review process, described in detail below, will result in a document which details the ways in which an application or vendor product conforms to the Architecture Design Document and is in agreement with the TIPSTER Architecture design. This document is a TIPSTER Application Conformance Assessment Document (TACAD).

In order for an application or vendor product to successfully acquire a TACAD, the following conditions must be met:

For TIPSTER Application development:

- The TIPSTER Application development complies with the TIPSTER CM process, the details which are contained in this document. In short, the TIPSTER Application must undergo a Preliminary Design Review (PDR) and a Final Operating Capability (FOC) review. At these reviews, any discrepancy or deviation from the TIPSTER Architecture must be documented and justified/explained.

- Any new code or capabilities for the TIPSTER Application must be developed in accordance with the TIPSTER Architecture. Failure to do so will be documented and justified in the TACAD.

- To the extent possible and in the Government's best interest, existing code and capability to be incorporated into the TIPSTER Application will be re-engineered in accordance with the TIPSTER Architecture. Failure to do so will be documented and justified in the TACAD.

For Vendor Products:

- If the vendor's product is used in a TIPSTER Application, the criteria stated above in "For TIPSTER Application development" will apply.

- A vendor's product may be determined to be TIPSTER compliant with the use of a TACAD independent of actually being part of a TIPSTER Application. To support the development of this TACAD, the vendor will demonstrate, by inspection, module-by-module compliance with the TIPSTER Architecture.

On the basis of the TACAD, the Configurations Control Board (CCB) will determine that a TIPSTER Application is conformant or non-conformant, if it exhibits sufficient overlap with the Architecture Design Document.

The extent of TIPSTER Conformance will be determined on a "per module" basis and documented in the TACAD. As a result of the TIPSTER Application reviews (described in section 1.2, below) a summary matrix will be available as shown in Appendix A, Figure A-1, below. 
The TACAD may be used by Vendors to facilitate teaming with other Vendors or insertions of new capability into existing TIPSTER systems.

\subsection{Configuration Management in a TIPSTER Application LifeCycle}

The TIPSTER CM process imposes two control gates, PDR and FOC, on the TIPSTER Application development lifecycle, as shown in Figure 1-2. In preparation for these control gates, it is expected that the developing contractor and the SE/CM will work together to prepare the documentation and to identify any discrepancies between the Architecture Design and the TIPSTER Application's design. This cooperation will be in the form of an Engineering Review Board (ERB).

At the PDR control gate, the following TIPSTER Application documentation is expected to be put in the TACAD and under TIPSTER CM control:

- 1. TIPSTER Application Design Documentation.

- 2. Documentation detailing any design discrepancy or deviations from the TIPSTER Architecture on a per-module basis. This document will also justify or explain the discrepancy or deviations found.

- 3. Any Requests For Change (RFC) to the TIPSTER Architecture to cover the discrepancy or deviations in the TACAD.

At the FOC control gate, the following are expected to be put in the TACAD and under TIPSTER CM control:

- 1. TIPSTER Application As-Built Documentation.

- 2. Documentation detailing any as-built discrepancy or deviations from the TIPSTER Architecture. This document will also explain the discrepancy or deviations.

- 3. Any Requests For Change (RFC) to the TIPSTER Architecture to cover the discrepancy or deviations.

It is expected that TIPSTER Applications will require control gates at the time of design and at the time of final delivery. The TIPSTER PDR and FOC control gates will 'piggy-back' on the projects control gates, to the maximum extent possible. 


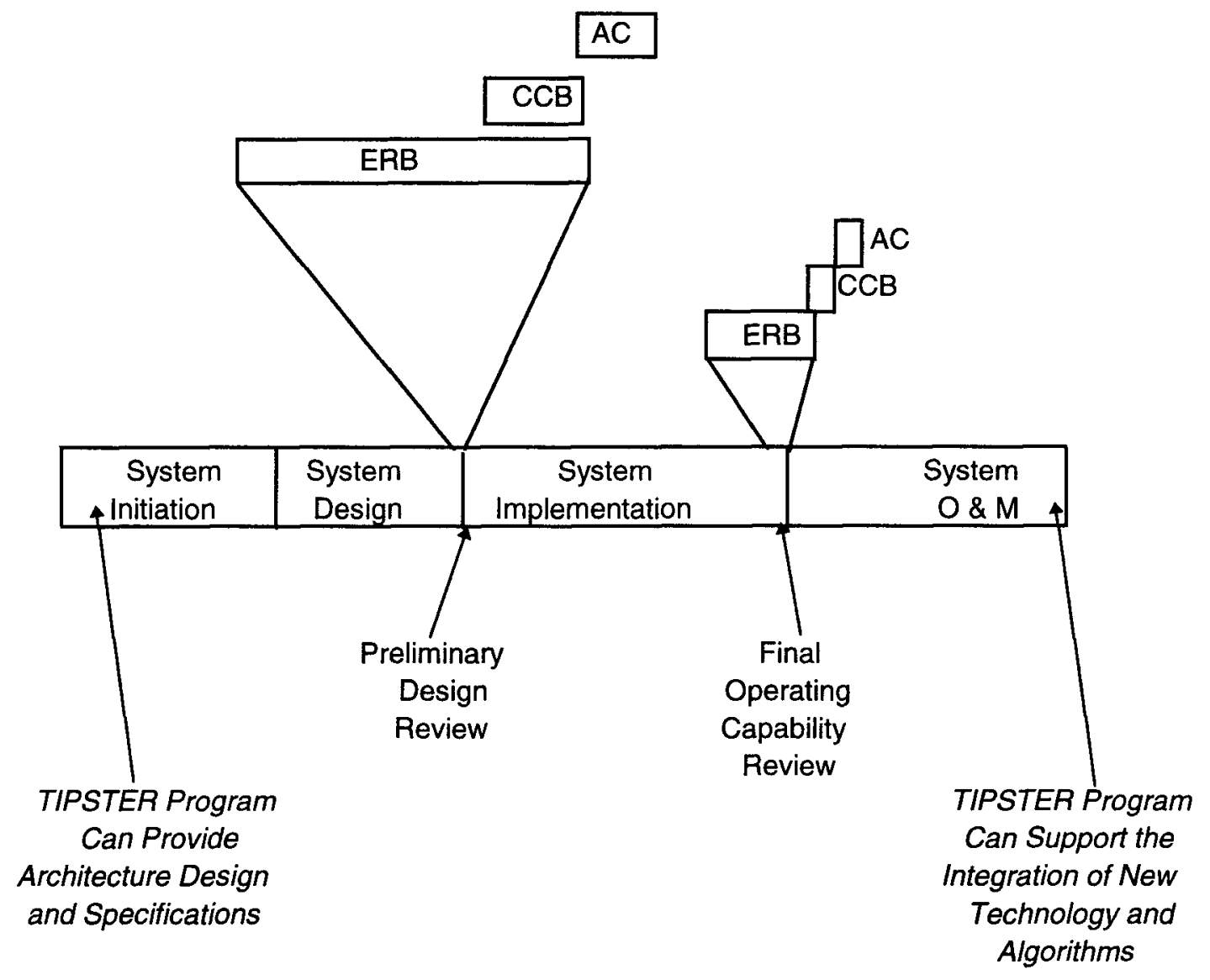

Figure 1-2 TIPSTER Application LifeCycle with Configuration Management Gates

The Architecture Committee will determine whether a TIPSTER Application has successfully passed a PDR and FOC control gate ERBs. In practice, the Architecture Committee will appoint a small group of people to sit on the Configuration Control Board (CCB) to examine, in detail, the documentation and justifications provided at the PDR and FOC control gates. The CCB will then make a recommendation to the Architecture Committee as to whether or not the control gate has been satisfied. The specifics of how to run the CCB and the control gates are given in Section 3.0, below.

The CCB will assign and use an Engineering Review Board (ERB) to compile the documentation necessary for the CCB's review. The ERB will be comprised of the SE/CM and the developing contractor's representatives. The specifics of how to run the ERB are given in Section 3.0, below.

Discrepancies will originate from the ERB and will primarily be presented by the developing contractor's representatives. The discrepancies will be submitted to the $\mathrm{CCB}$ for disposition, which can be one of the following:

- An RFC can be initiated to incorporate the discrepancy as a change to the Architecture Design Document.

- The discrepancy can be "Noted and Documented". This would assume that it is in the best interest of the Government to deviate from the Architecture in this particular case. 
- The discrepancy can be sent back to the developing contractor and the Government Contracting Officer's Technical Representative (COTR) with a request that the discrepancy be cleared up. 


\subsection{BACKGROUND}

\subsection{Need for TIPSTER Configuration Management}

Phase I of the TIPSTER Text Program, including the Text Retrieval Conference (TREC) and Message Understanding Conference (MUC) activities, produced a variety of advanced methods for text handling. However, incorporating the various algorithms and methods into usable applications under one TIPSTER Architecture requires close control and documentation of the constituent parts that comprise the TIPSTER II Architecture. This assumption is based on the following points:

- The detection and extraction systems were not developed to work together, although many important text processing tasks require interaction between detection and extraction technologies.

- Applications produced under Phase I have not been tested against the variety of tasks and natural languages that must be handled. The Government cannot treat every application requirement for natural language processing as a separate system; deployable systems must be flexible enough to handle a variety of tasks and languages with only minor modifications.

- Existing systems at both a component and module level implement similar functionality very differently. Standardizing on the Architecture and interfaces of a core set of such components and modules, so that they can be reused in many applications on many platforms, is the purpose of the TIPSTER Text Phase II Program. Specialized functions can have standard interfaces to operate with these core functions. This functional modularization will support the interoperability and flexibility that the Government believes is necessary to handle the variety and breadth of its text processing tasks. It will also reduce acquisition and maintenance costs and allow for the orderly expansion of an application's capability once deployed. Finally, functional modularization will support and advance the research community by making available a standardized, basic text handling architecture; no longer will an architecture have to be invented for every new experiment.

\subsection{SE/CM Role Within the Overall TIPSTER Framework}

The TIPSTER II SE/CM effort involves supporting the Government in overseeing the development of an open architecture and integration of components and modules for comprehensive text handling capabilities. This will allow processing of character streams and text databases from many disparate sources through content detection and data base or knowledge base update. In addition, tools and interfaces for configuring architecture components to particular applications must be integrated and managed.

Key issues in the development of the architecture requirements are defining the functions to be performed, the specific requirements of components and modules to perform each such function, particularly their input, output, and interface specifications, and also specifying an open architecture for integrating all components and modules. Key issues in the development of the Architecture itself are standardizing, documenting, and disseminating the module functional and interface specifications.

The role of the SE/CM contractor is best understood within the context of the overall TIPSTER framework. This framework includes three separate but interrelated set of activities: the SE/CM effort; the Architecture efforts; and the Demonstration Activities. Figure 2-1 depicts the respective functions of each activity set, and their interrelationships. The figure highlights the communications between SE/CM and the other activities, which will typically be in the form of architecture component requirements or description documents, and completed software modules. 


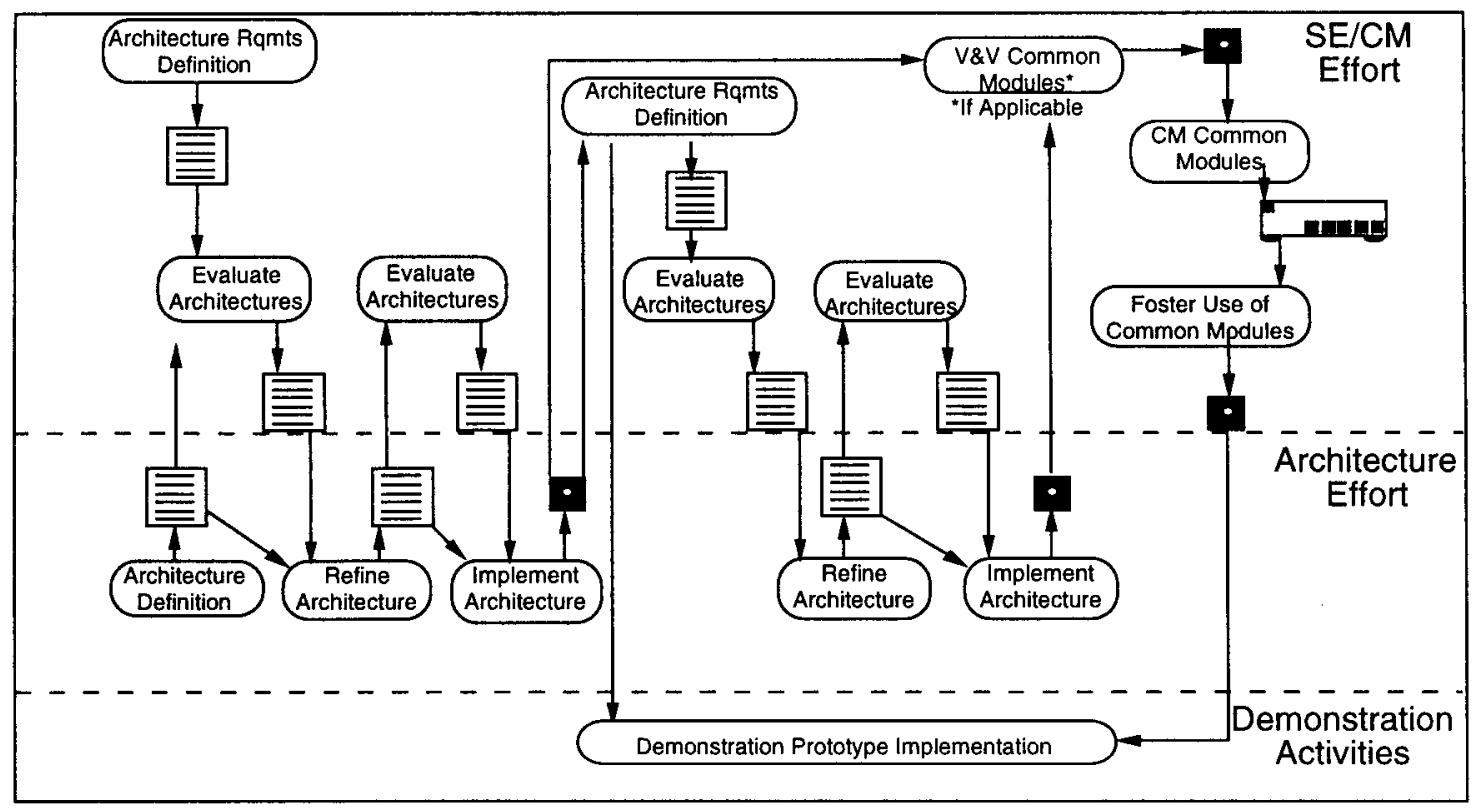

Figure 2-1 SE/CM Activities Related to Overall TIPSTER Framework

Initially, the architecture requirements will be defined from the existing TIPSTER I requirements, with the addition of requirements for integrating the most promising algorithms from that effort. The SE/CM will assist the Government in evaluating architectures proposed by TIPSTER II contractors. Later, as demonstration prototypes are initiated, their requirements must be analyzed to determine the adequacy of the existing architecture, and to define necessary or desirable enhancements.

Throughout this iterative process, the SE/CM will perform configuration identification activities including configuration definition, establishment of the Architecture baseline, review of applicable documentation and processing of Architectural changes. These activities will occur throughout the refinement effort and life of the Architecture. The SE/CM will work with the senior technical designers and engineers from all of the TIPSTER II teams to identify the Configuration Items (CIs). CM is responsible for gathering, storing, and presenting the current status of each configuration item.

\subsection{Purpose of the CM Plan}

The purpose of this plan is to establish guidelines, responsibilities, methods and procedures for $\mathrm{CM}$ for the TIPSTER Text Phase II Architecture. Specific procedures for CM are in related Configuration Management Procedures (CMPs). CM is intended to provide a stable and consistent definition of the TIPSTER Architecture.

\subsection{Scope of the CM Plan}

The scope of this plan encompasses anything related to the TIPSTER Architecture. As such, CM will be in effect during the life of the Architecture and will be primarily concerned with the documentation which describes the Architecture. It will not be applied to the software produced by the developers; CM for that software is the responsibility of the individual contractor.

The CM process is expected to become active at such time as the first Architecture baseline is established and CM will remain active throughout the life of the Architecture.

The CM process will monitor and control changes to the Architecture. Normally, changes to the baseline will be initiated when an TIPSTER Application has been designed and the PDR identifies potential deficiencies in the Architecture. 
Request For Changes (RFC) will go through the CM process and ultimately be approved by the Architecture Committee.

It is expected that the TIPSTER Architecture will continuously be undergoing growth and change. It is therefore vital that the CM process be able to reconstruct the exact state of the TIPSTER Architecture at any given date in the past.

Changes are categorized as either Class I, which is a change to the current Architecture baseline, or Class II, which is all other changes, such as correction of document typographical errors, resolution of ambiguities, and changes that clearly do not qualify as a Class I. Deviations are defined as discrepancies wherein an application does not conform to the particular Architectural standard.

\subsection{Plan Synopsis}

In addition to what was already noted in Section 1.2, this CM Plan defines the configuration management activities and philosophy required to support the TIPSTER Text Phase II Architecture throughout its entire life cycle. CM provides a means to identify, control, audit, and report on the configuration and status of the TIPSTER Architecture.

The remaining sections of this document provide information to effect quality change and release controls for TIPSTER II:

- Section 2.0 lists the referenced documents and the documents under CM which in turn define the Architecture at any time.

- Section 3.0 describes the relevant SE/CM configuration organizations for TIPSTER II. It also describes the $\mathrm{CM}$ roles and responsibilities of other program entities.

- Section 4.0 describes the general approach to $\mathrm{CM}$, CM responsibilities, and CM Phasing and Milestones.

- Section 5.0 has a glossary of all acronyms and abbreviations used in this CM Plan.

\subsection{Referenced and CM Documents}

The following documents were referenced in preparing this document.

- TIPSTER Configuration Management Procedure, CMP-1: Configuration Identification, TBD, PRC, Inc.

- TIPSTER Configuration Management Procedure, CMP-2: Change Control, TBD, PRC, Inc.

- TIPSTER Configuration Management Procedure, CMP-3: Configuration Auditing, TBD, PRC, Inc.

- TIPSTER Configuration Management Procedure, CMP-4: Configuration Status Accounting, TBD, PRC, Inc.

- Military Standard, Configuration Management, MIL-STD-973, 1 December 1992

- Configuration Management Manual, Software Engineering Guideline, May 1993, PRC, Inc.

The documents which will be placed under $\mathrm{CM}$ are:

- TIPSTER Requirements Document

- TIPSTER Architecture Design Document

- TIPSTER Architecture Interface Control Document

- TIPSTER Architecture Concept

- TIPSTER CM Plan

- TIPSTER Validation and Verification Plan

- TACAD 


\subsection{ORGANIZATION}

The structure, roles and responsibilities of the Configuration Management organization are defined in the paragraphs below.

\subsection{Organizational Structure}

The TIPSTER II SE/CM project employs a Configuration Management organization to establish CM procedures, oversee the application of these procedures by all team members and provide all necessary reports and support for the CM function. The overall TIPSTER Text Phase II program organization, depicted in Figure 3-1, identifies the relationship of the SE/CM support function with other TIPSTER components. This complex structure consists of the multi-agency Executive Committee and Architecture Committee, architecture contractors, demonstration and prototype development contractors, COTRs and the SE/CM contractor. Figure 3-2 illustrates the functional structure of the CM organization.

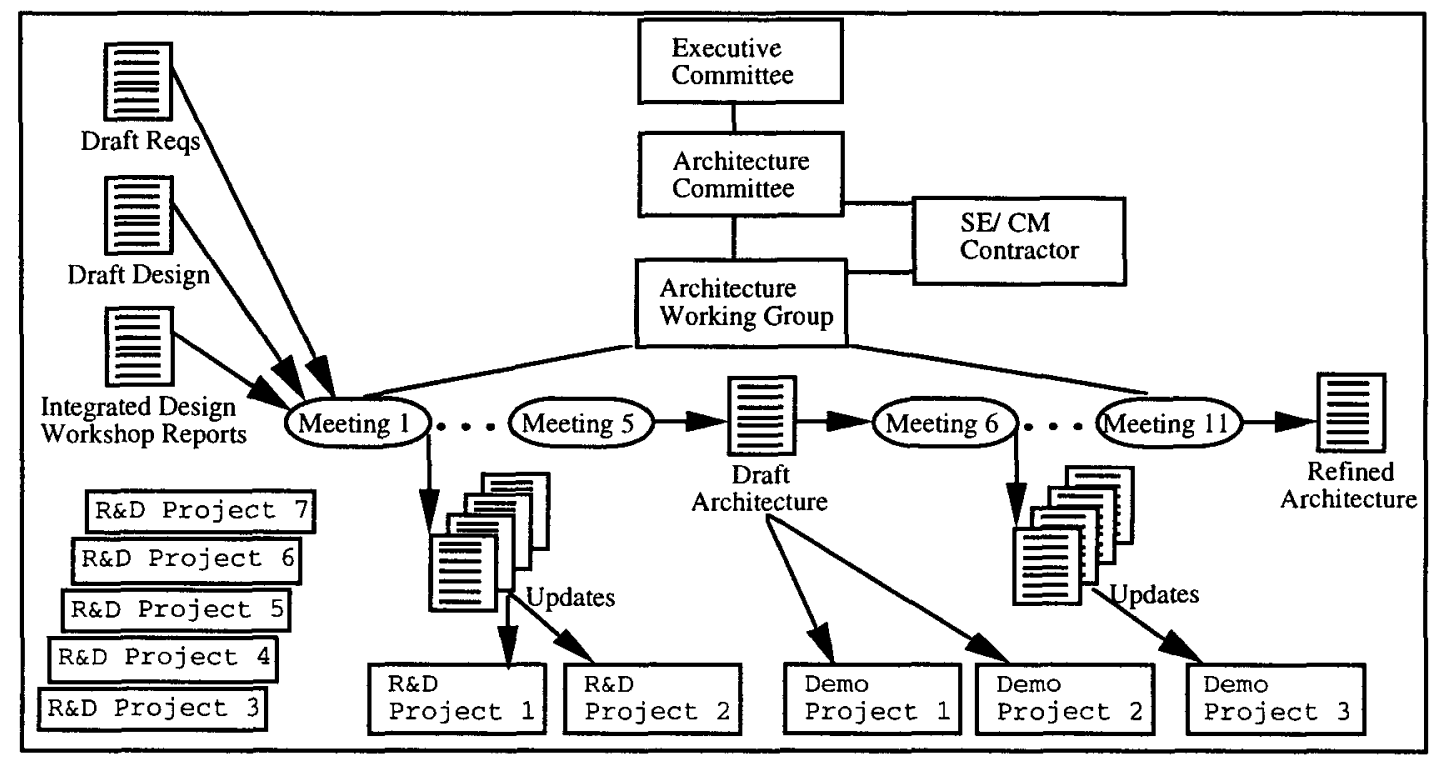

Figure 3-1 TIPSTER Text Phase II Organization 


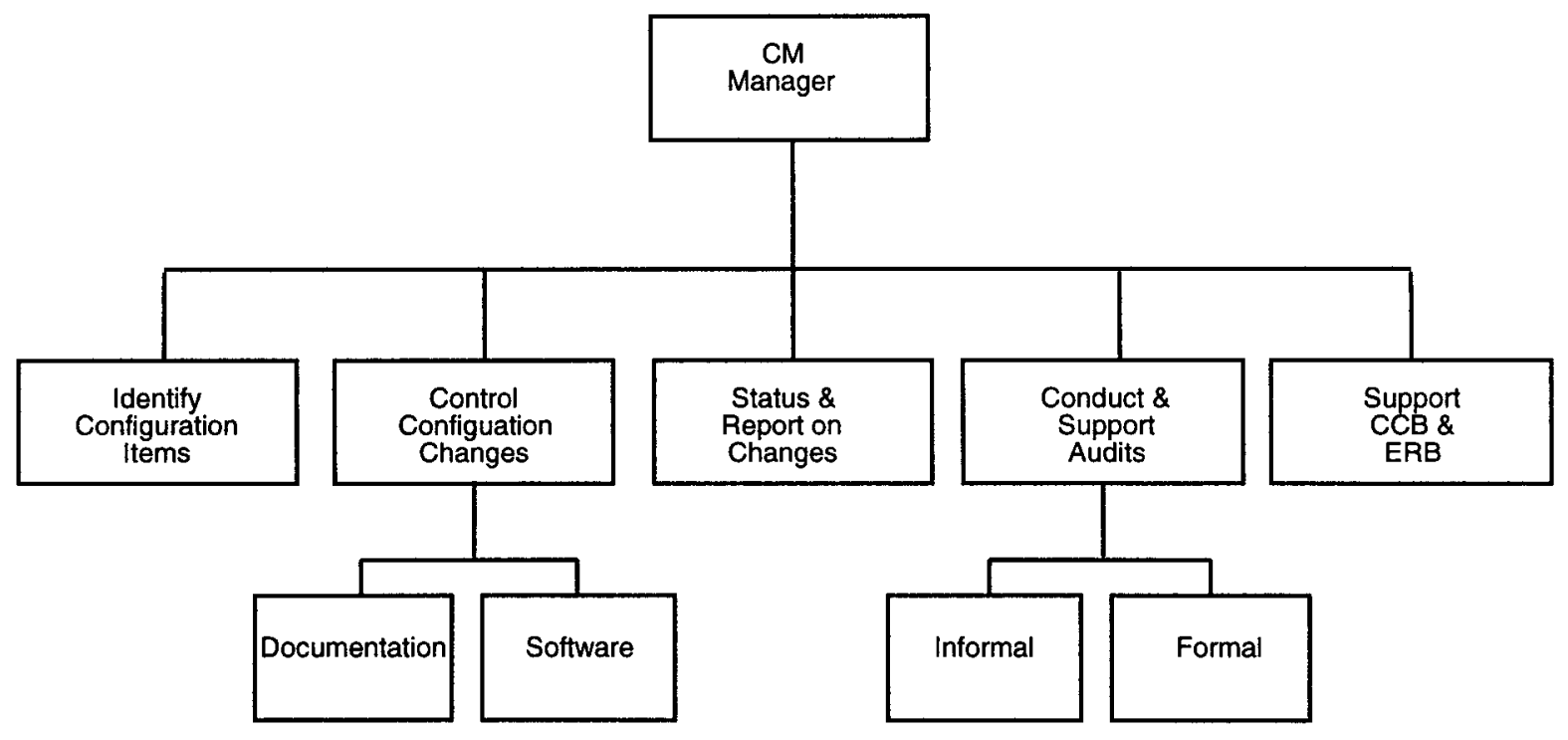

Figure 3-2 Configuration Management Functional Structure

\subsection{Roles and Responsibilities}

The following paragraphs describe the roles and responsibilities of each project element involved in the $\mathrm{CM}$ function. Figure 3-3 illustrates the organizational structure of the SE/CM organization.

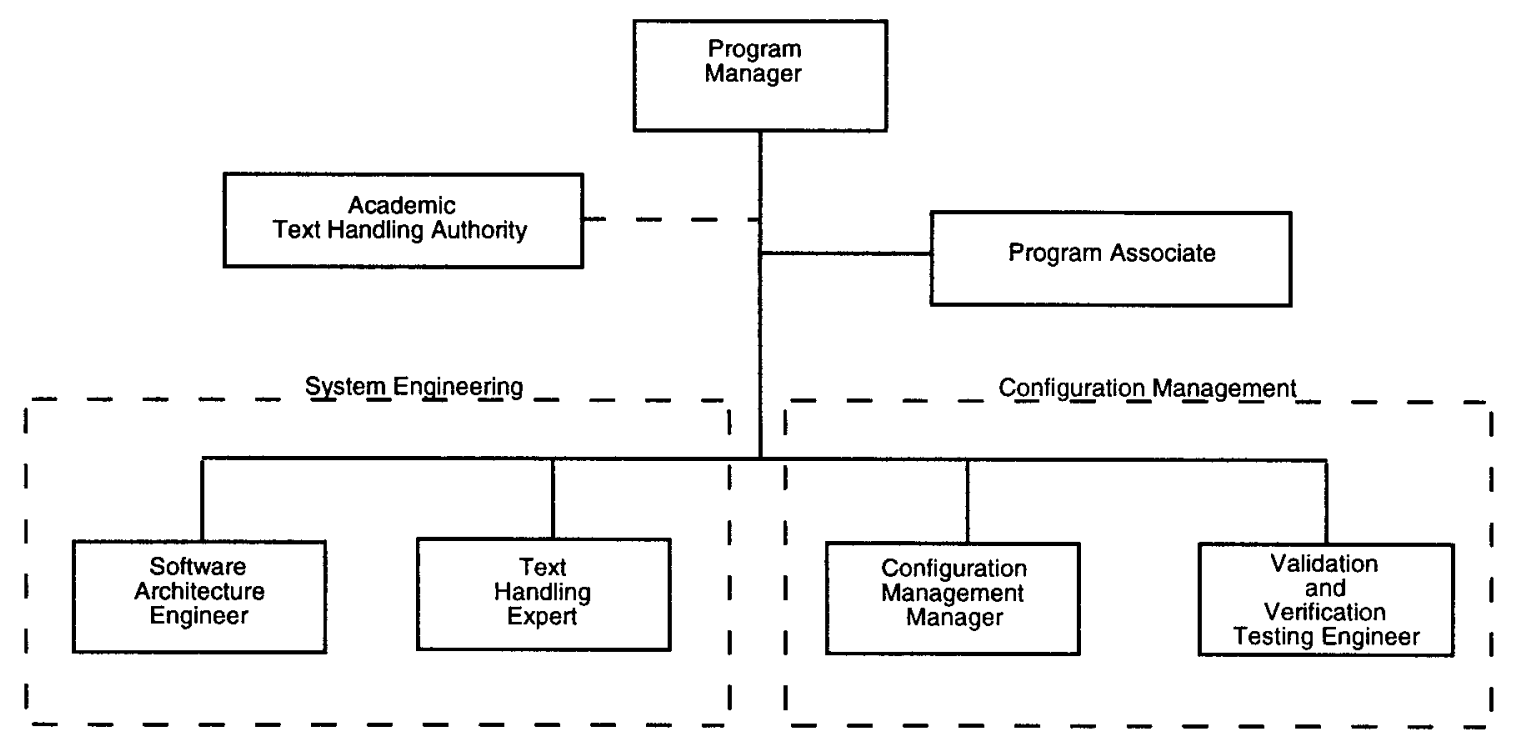

Figure 3-3 Organizational Structure of TIPSTER II SE/CM Support 


\subsubsection{SE/CM Program Manager}

The Program Manager (PM) assists the Chair of the Architecture Committee in meeting the objectives of the TIPSTER Architecture and Demonstration programs, with respect to requirements definition, coordination of disparate contractors and approaches, and supervision of the configuration management and verification/validation efforts. Compliance with the guidelines and procedures specified in this plan is the primary responsibility of the program manager along with the CM Manager (CMM). The PM is responsible for approving the tailoring of CM policies, practices, and procedures to ensure that adequate methods are implemented for identification and control of the TIPSTER Architecture.

The Program Manager ensures that:

- Adequate $\mathrm{CM}$ resources, including $\mathrm{CM}$ tools, are made available.

- $\mathrm{CM}$ plans and procedures are approved by the Architecture Committee Chair.

- Documented and approved CM practices and procedures are followed by all team members.

- $\mathrm{CM}$ personnel are trained in the objectives, procedures, and methods for performing their assigned $\mathrm{CM}$ activities.

- $\mathrm{CM}$ requirements, processes, and practices are conveyed to all TIPSTER team members for compliance.

\subsubsection{Configuration Management Manager}

The CM Manager (CMM) will report to the TIPSTER SE/CM Program Manager. The CMM is responsible for (a) implementing a CM system which is tailored for the unique features of the TIPSTER Text Phase II Program and (b) developing CM procedures to assure control of documentation. To support the preparation of configuration status reports, the CMM maintains a database containing the change status of all Architecture elements and changes.

To assure the integrity of all items placed within $\mathrm{CM}$ control, the CMM establishes and maintains both electronic and hard copy libraries with access limited to $\mathrm{CM}$ personnel. The CMM acts as the point of contact for receiving and processing information from external organizations. Incoming and outgoing shipments of $\mathrm{CM}$ controlled items will be handled by the CMM. The CMM is also responsible for performing and supporting both formal and informal audits conducted at appropriate milestones during the Architecture life cycle.

The CMM is a regular participant in all ERB and CCB meetings. The role of the CMM is to schedule these meetings, provide an agenda, record and disseminate minutes, and track action items.

The CMM, in performing the foregoing responsibilities, will have the independence and authority to coordinate and communicate $\mathrm{CM}$ functions with management and technical personnel involved in the Architecture effort. All management and technical personnel are required to be familiar with and comply with the provisions of this $\mathrm{CM}$ plan, as well as being responsible for certain configuration activities in support of CM functions. The following Table 3-1, CM Responsibilities and Relationships, is a matrix of the major CM functions and responsibilities of various management and technical personnel. 


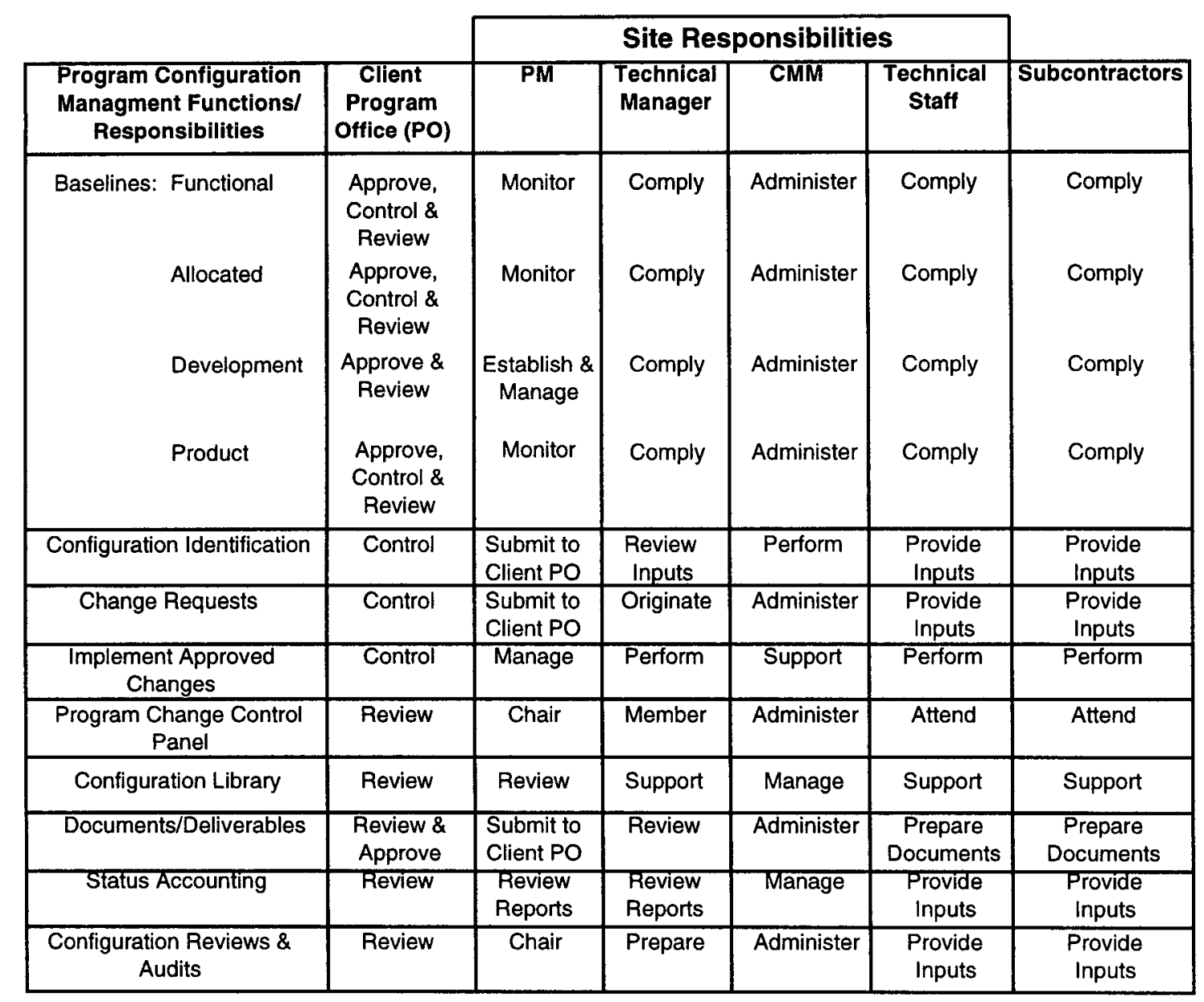

Table 3-1 CM Responsibilities and Relationships

\subsubsection{Software Architecture Engineer}

A software architecture engineer will assist the Architecture Committee Chair by performing certain CM tasks. These tasks consist of reviewing/analyzing problem reports and change requests, and preparing recommendations to effect proposed changes or preparing a statement why the proposed change should not be made to the Architecture.

\subsubsection{Verification and Validation Testing Engineer}

The Verification and Validation (V\&V) Testing Engineer will develop and implement tests to determine if modules in TIPSTER Applications are consistent with the Architecture Design Document by ensuring that they conform to the specifics in the Architecture Design Document.

Additionally, if necessary, the V\&V Test Engineer will determine that shared components and modules interface as required, both in isolation and in combination with the other components and modules. Specifically, the interfaces must be as described in the TIPSTER Interface Control Document. Internal component processing capabilities do not come under the scope of V\& V Testing. (See V\&V Test Plan). The V\&V Testing Engineer controls formal CSCI test procedure development prior to those components being placed under formal $\mathrm{CM}$ control, reports problems identified during formal CSCI testing to CM, and actively participates in ERB and CCB meetings.

\subsubsection{Configuration Control Board (CCB)}

The CCB is the Government review and action board comprised of key personnel from the Architecture Committee, $\mathrm{SE} / \mathrm{CM}$, and the appropriate contractors. The $\mathrm{CCB}$ provides a central point of coordination of changes to the 
baseline Architecture. The CCB is the focal point and the source of direction for implementation of Class I changes to the TIPSTER II Architecture.

The CCB reviews each Class I change and makes a decision as to the disposition with the options of (a) approve the change, (b) disapprove the change, or (c) defer the proposed change. Each board member is allowed to state his/her official position on the proposed change. However, the CCB is a non-voting board. Thus, the CCB Chairman shall render the final decision as to the course of action to the taken. The CCB's decision is recorded as a Change Directive.

The CCB's major responsibilities are:

- Review all proposed change requests.

- Assess change impacts.

- Provide a statement that the application development which initiated a change is in compliance with the Architecture or represents a deviation from the Architecture.

- Review modifications to all documentation .

- The results of any actions taken by the CCB are reported to the Architecture Committee.

The membership of the CCB is:

- Architecture Committee Chair (CCB Chair)

- DIA Representative (Member)

- NSA Representative (Member)

- CIA Representative (Member)

- $\quad$ TIPSTER ARPA PM (Guest Member)

- $\mathrm{SE} / \mathrm{CM}$ Project Manager (Advisor)

- SE/CM Configuration Management Manager (Secretary)

- Software Architecture Engineer (Advisor)

Other key personnel will be assigned to the $\mathrm{CCB}$ as the Chair may deem necessary to resolve particular issues. The $\mathrm{CCB}$ Chair will conduct the meeting and render the final decision to the course of action to be taken.

The above members form the core of the CCB. If a member is unable to attend a meeting, he/she must designate a representative to attend in his/her place. The representative must have full authority to act on behalf of the missing member. Additional individuals are invited to participate, as appropriate, when their technical expertise is required.

\subsubsection{Engineering Review Board (ERB)}

The ERB is an internal TIPSTER II Architecture review and action panel comprised of personnel from all project groups. Membership of the ERB is:

- $\quad$ SE/CM Program Manager (Chair)

- The TIPSTER Application Contracting Officer's Technical Representative (COTR)

- Supporting Agency-Specific Representative (TIPSTER expertise)

- CM Manager (Secretary)

- Contractor Group Representative(s) (Member)

- Software Architecture Engineer (Member)

The objectives of the ERB are disposition of problems, classification of proposed changes, and disposition of Class II changes. Upon receipt and disposition of a problem, the ERB will analyze it for type of problem, priority, and verification of the proposed solution. When the problem is fixed, the ERB will determine the implementation 
schedule of the fix into the affected baselines. Upon review of a change request, the ERB first determines the classification as either a Class I or Class II type of change. For Class I changes, the ERB assigns preparation of a Request For Change (RFC) to the responsible groups for submittal to the CCB for their review and disposition. Class II changes are within the scope of authority of the ERB for disposition. The ERB reviews each Class II change and then takes appropriate action for its disposition. Each panel member is allowed to state his/her position on the change. However, the ERB is a non-voting board. Thus, the ERB chairman shall render final decision as to the course of action to be taken. ERB decisions are recorded on Change Directives, a copy of which is sent to the CCB for information only.

\subsubsection{Architecture Committee}

The Architecture Committee has final authority over the TIPSTER Architecture and in this role can accept or reject any Change Directive reported by the CCB.

The Architecture Committee appoints the members of the CCB.

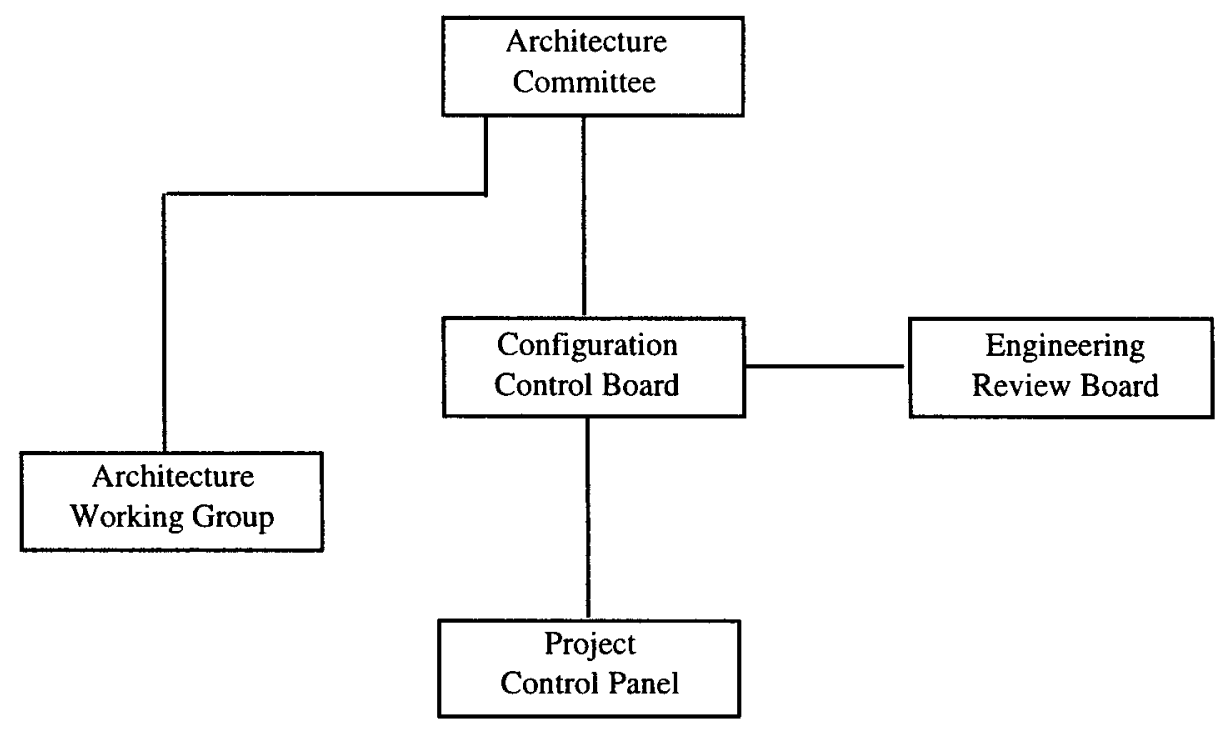

Figure 3-4 CM Organization

\subsubsection{Architecture Working Group (AWG)}

Since the CM function does not start until the Architecture baseline has been released by the Architecture Working Group (AWG), it will have no CM responsibility.

\subsubsection{Evaluation Working Group}

The TIPSTER Phase II evaluation working group (EWG) is tasked with designing, implementing, and coordinating evaluations intended to demonstrate the effectiveness of TIPSTER architectural approaches; thus, the EWG will be a user of the results of the $\mathrm{CM}$ process by using the appropriate Architectural version in their evaluations.

The membership of the EWG is composed of the following core personnel:

- Chairperson

- SE/CM Representative

- 2 NSA Representatives 
- 2 CIA Representatives

- 1 BBN/UMass Representative

- $1 \mathrm{MMC} / \mathrm{GE}$ Representative

- Representatives from the other contractors

The membership of the EWG is composed of the following adjunct participants:

- Evaluation Representatives (TREC, MUC)

- Demonstration Representatives (Sponsor/Contractor - 2 persons) 



\subsection{CONFIGURATION MANAGEMENT ACTIVITIES}

\subsection{TIPSTER CM Approach}

The CM organization is responsible for identifying the specific items that define the Architecture and will be configuration controlled, as well as when and how they are to be controlled. CM conducts audits of the Architecture baseline to ensure conformance with the TIPSTER concept and to verify that the configuration management library system is functioning adequately.

\subsection{Configuration Management Responsibilities}

TIPSTER's CM responsibilities comprise baseline management, interface control, and the $\mathrm{CM}$ aspects of quality control in each of the following six areas which operate throughout the Architecture's life cycle:

- Item and baseline identification and management

- Configuration control

- Configuration status accounting (CSA)

- Configuration audits

- Architecture file maintenance

- Architecture delivery

In the area of item and baseline identification and management, configuration management is responsible for baseline traceability and integrity by retention of all versions and releases of Architecture elements.

As stated in Section 1, once an element is part of the baseline, it is placed under change control. In this area, configuration management has many responsibilities. These include administrative handling of all changes, from initial receipt and logging of Change Requests through issuance of Change Directives indicating final disposition. Configuration management prepares, publishes, and incorporates the change pages in the defining documentation. Configuration management personnel also act as the recording secretary for the two project change review organizations: the Engineering Review Board (ERB) and the Configuration Control Board (CCB).

Configuration management has this status accounting responsibility where in monthly status reports for changes, problems, and action items are reported.

Architecture files contain all written materials and documentation on the TIPSTER II Architecture. This critical area is the responsibility of configuration management.

Finally, configuration management is responsible for formal delivery of all TIPSTER II Architecture defining documents to the Government.

\subsection{Configuration Management Phasing and Milestones}

The CM activities described in this CM Plan are initiated and completed in accordance with the Program Master Schedule. Table 4-1 is a list of major events/milestones and specifies the CM activities conducted and the planned dates for initiation and completion of each event/milestone. 


\begin{tabular}{|l|l|l|l|}
\hline Events/Milestones & CM Activities & Start Date & Finish Date \\
\hline $\begin{array}{l}\text { Requirements } \\
\text { Definition }\end{array}$ & $\begin{array}{l}\text { Initiate status accounting for action items, } \\
\text { Establish project files }\end{array}$ & $00 / 00 / 00$ \\
\hline $\begin{array}{l}\text { Commence } \\
\text { Manfiguration }\end{array}$ & $\begin{array}{l}\text { Establish Architecture Baseline, Initiate change } \\
\text { control, Initiate "Version Description Document" } \\
\text { Initiate status accounting for changes, and continue } \\
\text { Action Items Maintain project files }\end{array}$ & $\begin{array}{l}\text { Identify Configuration Items, Continue change } \\
\text { control, Continue status accounting for changes and } \\
\text { action items, Maintain project files, Deliver } \\
\text { architecture documents }\end{array}$ & \\
\hline CM Setup & $\begin{array}{l}\text { Process changes, identify Architectural Deviations, } \\
\text { Continue change control, Update "Version } \\
\text { Description Document", Continue status accounting } \\
\text { for changes and Action Items, Maintain project files }\end{array}$ & & \\
\hline $\begin{array}{l}\text { Preliminary Deview (PDR) } \\
\text { Design }\end{array}$ & $\begin{array}{l}\text { Issue Architecture Deviation Document Continue } \\
\text { change control, Update "Version Description } \\
\text { Document", Continue status accounting for changes } \\
\text { and action items, Maintain project files, }\end{array}$ & & \\
\hline $\begin{array}{l}\text { Final Operating } \\
\text { Capability (FOC) }\end{array}$ &
\end{tabular}

Table 4-1 CM Events and Milestones -

\subsection{Architecture Request For Change Process}

\subsubsection{The Goal}

The SE/CM has five major goals with respect to the RFC process for the TIPSTER Architecture. They are as follows:

- Provide for consistency in the development of the Architecture.

- Allow for changes, proposed on the basis of different versions of the Architecture, to be combined into a single change.

- Provide for consideration of changes proposed by any interested party.

- Encourage changes to the Architecture from anyone who has done an implementation.

- Provide for independent submission and review of proposed changes.

\subsubsection{Overview - Submitter/Reviewer}

Submissions of RFCs can come from any source. It is expected that submissions will be made by application developers, the CAWG, or the SE/CM.

\subsubsection{Application Developer Submission}

Submissions from applications developers will be reviewed by the SE/CM and approved/disapproved by the Architecture Committee. As reviewer, the SE/CM will recommend minor modifications to the RFC to maintain a level of consistency in names and methods. If major modifications are necessary, the SE/CM may submit an entirely new RFC. The Architecture Committee will then have both RFCs to approve/disapprove.

The CAWG will be able to evaluate the proposed changes and make suggestions to the SE/CM or the Architecture Committee. Any comments/recommendations by the CAWG will be an addendum to the formal RFC. 
As a minimum, the CAWG will receive the RFC when it is formally submitted to the SE/CM. Under normal circumstances, however, the SE/CM will be aware that changes are likely to be forthcoming from an application under development. In such cases, the SE/CM will keep the CAWG informed of the issue under discussion. In this way, the CAWG may be able to provide timely input to the application developer as to previously debated issues or 'known' work-arounds for the difficulty encountered.

\subsubsection{CAWG Submission}

Submissions from the CAWG will be reviewed by the SE/CM and approved/disapproved by the Architecture Committee. As reviewer, the SE/CM may recommend minor modifications to the RFC to maintain a level of consistency in names and methods.

\subsubsection{SE/CM Submission}

On rare occasions, submissions may come from the SE/CM and will be reviewed by the CAWG or other person(s) as designated by the Architecture Committee and approved/disapproved by the Architecture Committee. The reviewer may recommend minor modifications to the RFC to maintain a level of consistency in names and methods.

If the reviewer is not the CAWG, the SE/CM will keep the CAWG informed of the issue under discussion. In this way, the CAWG will be able to provide comments and recommendations to the Architecture Committee.

\subsubsection{Tracking of RFCs}

RFCs will be formally tracked by their RFC number. The RFC will contain the following:

- Status/Routing Sheet

- Submission Form

- Review Sheet

- CAWG Comments or Recommendations

- Any Relevant Material Such as Email Traffic

The RFCs will be available on the internet on the TIPSTER web page 


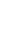




\subsection{GLOSSARY AND LIST OF ABBREVIATIONS}

The terms and abbreviations listed below are used within this CM Plan. Their meanings are provided for the reader's convenience.

$\begin{array}{ll}\text { API } & \text { Application Program Interface } \\ \text { ARPA } & \text { Advanced Research Projects Agency } \\ \text { AWG } & \text { Architecture Working Group } \\ \text { BBN } & \text { Bolt Beranek and Newman } \\ \text { CCB } & \text { Configuration Control Board } \\ \text { CI } & \text { Configuration Item } \\ \text { CIA } & \text { Central Intelligence Agency } \\ \text { CM } & \text { Configuration Management } \\ \text { CMM } & \text { Configuration Management Manager } \\ \text { CMP } & \text { Configuration Management Procedures } \\ \text { COTR } & \text { Contracting Officer's Technical Representative } \\ \text { CSA } & \text { Configuration Status Accounting } \\ \text { CSCI } & \text { Computer Software Configuration Item } \\ \text { DIA } & \text { Defense Intelligence Agency } \\ \text { ERB } & \text { Engineering Review Board } \\ \text { EWG } & \text { Evaluation Working Group } \\ \text { FCA } & \text { Functional Configuration Audit } \\ \text { FOC } & \text { Final Operating Capability } \\ \text { GE } & \text { General Electric } \\ \text { ICD } & \text { Interface Control Document } \\ \text { MMC } & \text { Martin Marietta Corporation } \\ \text { MUC } & \text { Message Understanding Conference } \\ \text { NSA } & \text { National Security Agency } \\ \text { PCA } & \text { Physical Configuration Audit } \\ \text { PDR } & \text { Preliminary Design Review } \\ \text { PM } & \text { Program Manager } \\ \text { PO } & \text { Program Office } \\ \text { QA } & \text { Quality Assurance } \\ \text { RFC } & \text { Request For Change } \\ \text { SE } & \text { Systems Engineering } \\ \text { SE/CM } & \text { Systems Engineering/Configuration Management } \\ \text { TACAD } & \text { TIPSTER Application Conformance Assessment Document } \\ & \end{array}$


TBD

To Be Decided

TREC

Text Retrieval Conference

UMass

University of Massachusetts

V\&V

Verification and Validation 


\section{APPENDIX A TACAD DESCRIPTION}

\begin{tabular}{|l|l|l|}
\hline \multicolumn{1}{|c|}{$\begin{array}{c}\text { TIPSTER Design } \\
\text { Module }\end{array}$} & Application Module & \multicolumn{1}{c|}{ Comment } \\
\hline Get Document & Next Message & Fully Compliant \\
\hline Find Name & Namer & Partially Compliant - see section 13.4 for details. \\
\hline & & \\
\hline & & \\
\hline & & \\
\hline
\end{tabular}

Figure A-1 TIPSTER Compliance Based on Modules 



\section{APPENDIX B REQUEST FOR CHANGE}

TIPSTER ARCHITECTURE

REQUEST FOR CHANGE (RFC) FORM

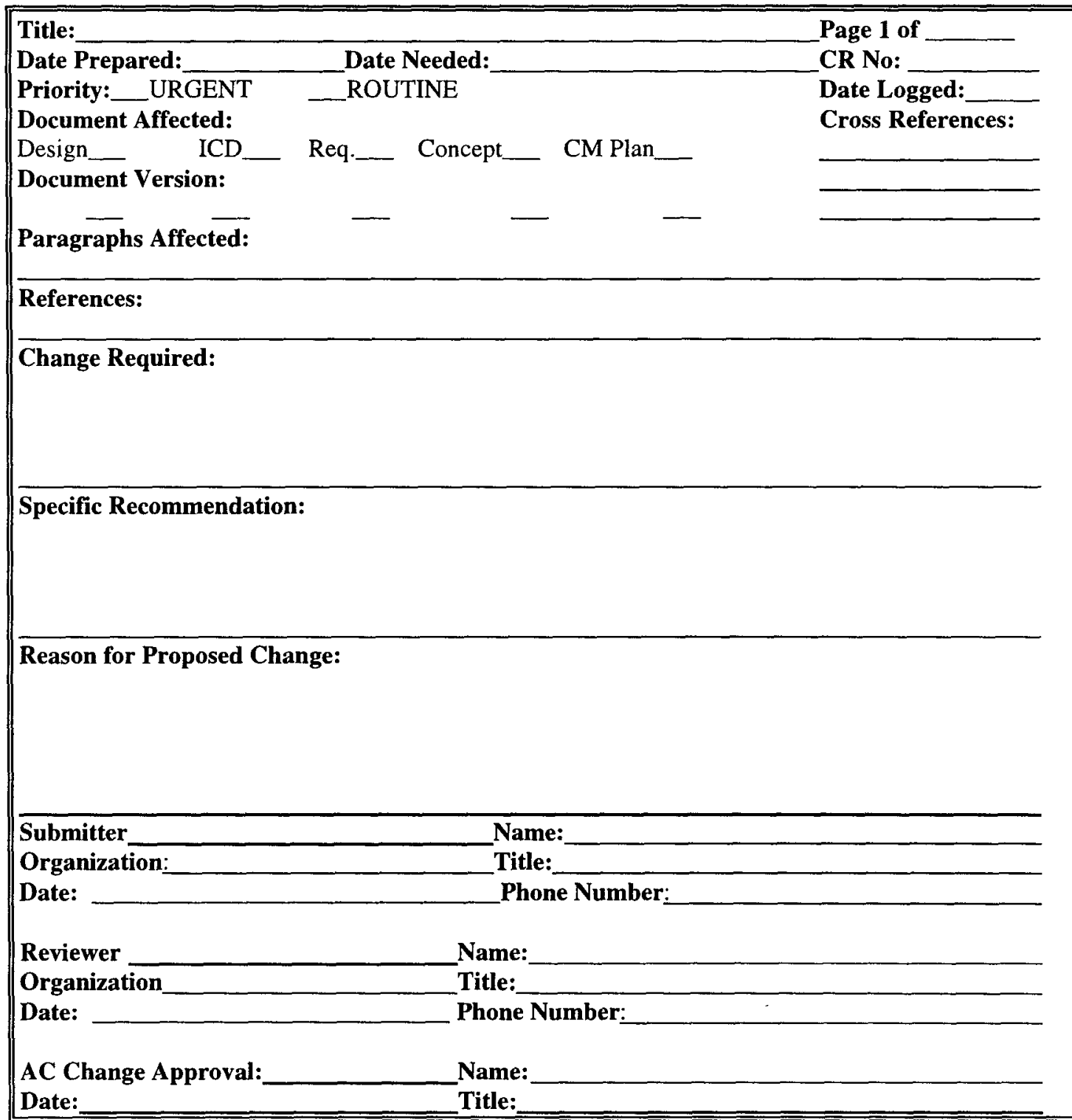


REQUEST FOR CHANGE (RFC) FORM INSTRUCTIONS

\begin{tabular}{|c|c|c|}
\hline Field & Instructions & Responsibility \\
\hline Title & $\begin{array}{l}\text { Enter short ( } 10 \text { words or less), descriptive title for the } \\
\text { Change Request. }\end{array}$ & Submitter \\
\hline Page 1 of & $\begin{array}{l}\text { Enter total number of pages, including any supporting } \\
\text { information and this form. }\end{array}$ & $\mathrm{CM}$ \\
\hline Date Prepared & $\begin{array}{l}\text { Enter date requestor prepares } \mathrm{CR} \text {, including all } \\
\text { attachments. }\end{array}$ & Submitter \\
\hline Need Date & $\begin{array}{l}\text { Enter date by which decision must be received by the } \\
\text { requestor to avoid any or additional impact. }\end{array}$ & Submitter \\
\hline Priority & $\begin{array}{l}\text { Check appropriate selection. A CR is urgent if work } \\
\text { cannot proceed without a decision on the request. }\end{array}$ & Submitter \\
\hline $\begin{array}{l}\text { Document } \\
\text { Affected }\end{array}$ & Check all documents affected by the requested change & Submitter \\
\hline Version Affected & Enter the version number of the above document. & Submitter \\
\hline $\begin{array}{l}\text { Paragraph } \\
\text { Affected }\end{array}$ & $\begin{array}{l}\text { Enter the paragraph numbers requiring change. Indicate } \\
\text { document by } D, I, R, C \text {, or } P\end{array}$ & Submitter \\
\hline Reference & $\begin{array}{l}\text { Specify reference document(s), such as meeting minutes, } \\
\text { from which the CR was initiated. If not applicable, enter } \\
\text { N/A. }\end{array}$ & Submitter \\
\hline CR No. & $\begin{array}{l}\text { Assign Change Request number in the form of NNNNN } \\
\text { where NNNNN is the sequence number. }\end{array}$ & $\mathrm{CM}$ \\
\hline Date Logged & Enter date $\mathrm{CR}$ is received by $\mathrm{CM}$. & $\mathrm{CM}$ \\
\hline Cross References & Internal CM use, 3 lines & CM \\
\hline Change Required & $\begin{array}{l}\text { Describe in detail what change(s) is (are) required. The } \\
\text { "how" of the change is covered under the next item. }\end{array}$ & Requestor \\
\hline $\begin{array}{l}\text { Specific } \\
\text { Recommendation }\end{array}$ & $\begin{array}{l}\text { Attach redlined pages from the affected documents. } \\
\text { Redlines must be clear, precise, and all-inclusive. Specify } \\
\text { how the change is to be made, as applicable. For example, } \\
\text { if an ICD module specifications is requested to be } \\
\text { changed, the appropriate pages from the ICD would be } \\
\text { attached and redlined with the proposed change. If the } \\
\text { change would cause other changes, those pages must also } \\
\text { be attached and redlined. }\end{array}$ & Requestor \\
\hline $\begin{array}{l}\text { Reason for } \\
\text { Proposed Change }\end{array}$ & $\begin{array}{l}\text { Provide justification, in detail, for the proposed change. } \\
\text { Include alternative solutions, if available, and impact if } \\
\text { change is not implemented. }\end{array}$ & Requestor \\
\hline Subnitter & Enter organization, requestor name, title and date & Requestor \\
\hline Reviewer & $\begin{array}{l}\text { Enter name, title and date of reviewing official, normally } \\
\text { SE/CM unless submitted by SE/CM; then appointed by AC }\end{array}$ & $\mathrm{CM}$ \\
\hline $\begin{array}{l}\text { AC Change } \\
\text { Approval }\end{array}$ & Enter name, title and date of approving official & AC Chairperson \\
\hline
\end{tabular}

